\title{
ANALISIS KETERLAMBATAN KEGIATAN SHIP TO SHIP (STS) PADA NIPAH TRANSIT ANCHORAGE AREA (NTAA) YANG DIAGENI OLEH PT ADHIGANA PRATAMA MULYA
}

\author{
Cici Thamelda Latief ${ }^{1)}$ Marthen Makahaube ${ }^{2)}$ Sunarlia Limbong ${ }^{3)}$ \\ Politeknik IImu Pelayaran Makassar \\ Jalan Tentara Pelajar No. 173 Makassar, Kode pos. \\ 90172 Telp. (0411) 3616975; Fax (0411) 3628732 \\ E-mail: pipmks@pipmakassar.com
}

\begin{abstract}
ABSTRAK
Tujuan penelitian ini yaitu mengetahui faktor-faktor apa saja yang menyebabkan kendala pada saat kegiatan Ship To Ship (STS) di Nipah Transit Anchorage Area (NTAA). Penelitian ini dilaksanakan di Perusahaan Pelayaran saat Taruna melaksanakan praktek darat selama 11 bulan pada PT Adhigana Pratama Mulya dan satu bulan pada Kantor Kesyahbandaran dan Otoritas Pelabuhan Kelas I Tanjung Balai Karimun. Jenis penelitian ini adalah Deskriptif Kualitatif, yaitu data yang diperoleh berupa informasi-informasi pembahasan pada data keagenan kapal untuk kegiatan Ship To Ship (STS) yang diperoleh secara lisan maupun tulisan. Hasil penelitian menunjukkan bahwa Beberapa sertifikat kapal yang masa berlakunya telah habis dan harus diperbaharui dan kurangnyaa perawatan alat bongkar muat yang dilakukan oleh kru kapal.
\end{abstract}

Kata Kunci: Keterkambatan, Ship To Ship, Keagenan.

\section{PENDAHULUAN}

Pada proses pelaksanaan kegiatan Ship To Ship (STS) beberapa kali mengalami keterlambatan dikarenakan beberapa kendala baik dari faktor internal maupun faktor eksternal. Sehubungan dengan fakta-fakta di atas maka penulis tertarik untuk meneliti dan membahas masalah "Analisis Keterlambatan Kegiatan Ship To Ship (STS) pada Nipah Transit Anchorage Area (NTAA) yang Diageni oleh PT Adhigana Pratama Mulya."

Berdasarkan latar belakang yang telah dikemukakan di atas, maka yang menjadi masalah dalam penelitian ini adalah faktor-faktor apa saja 
yang menyebabkan kendala pada saat kegiatan Ship To Ship (STS) di Nipah Transit Anchorage Area (NTAA)?

Tujuan dari penelitian yang dilakukan adalah untuk mengetahui faktor-faktor apa saja yang menyebabkan kendala pada saat kegiatan Ship To Ship (STS) di Nipah Transit Anchorage Area (NTAA).

Kota Batam adalah sebuah kota terbesar di Provinsi Kepulauan Riau, Indonesia. Batam dikenal sebagai daerah pelabuhan bebas paling ramai dikunjungi oleh pelaut kapal asing di Indonesia, apalagi sejak diberlakukannya Free Trade Zone (FTZ) atau daerah perdagangan bebas untuk kawasan BBK (Batam, Bintan, Karimun) setidaknya ada tujuh tempat anchorage area (lepas jangkar atau labuh jangkar) kapal di perairan Batam dan sekitarnya, salah satunya Nipah Transit Anchorage Area (NTAA). Pulau Nipah, pulau paling luar disebelah utara pulau Batam yang berbatasan langsung dengan negeri Singapura di Selat Malaka dan Singapore Straits ini, saat ini sudah diizinkan oleh Dinas Perhubungan Pusat untuk dijadikan daerah Ship To Ship (STS) atau transfer muatan khususnya untuk kapal bertonase besar seperti Very Large Cargo Carrie (VLCC).

PT Adhigana Pratama Mulya merupakan perusahaan pelayaran yang bergerak dibidang jasa keagenan kapal sebagai General Agent dan Sub Agent. Yang dimana General Agent sebagai perantara antara Owner dan Sub Agent yang diageni oleh perusahaan PT Adhigana Pratama Mulya. Sedangkan Sub Agent PT Adhigana Pratama Mulya menangani khusus kapal asing bermuatan LPG/C dan oil tanker yang masuk pada wilayah Batam dan perairan Pulau Nipah.

Pada saat pelaksanaan bongkar muatan secara Ship To Ship (STS), sering kali terjadi kendala yang mengakibatkan keterlambatan proses bongkar muatan, antara lain dalam proses pengurusan dokumen, 
kondisi alat bongkar muat yang kurang terawat, cuaca buruk serta kurangnya koordinasi yang baik antar pihak terkait.

\section{METODOLOGI PENELITIAN}

Metode penelitian merupakan suatu usaha untuk menemukan, mengembangkan dan menguji kebenaran ilmu pengetahuan secara ilmiah. Penelitian atau riset adalah terjemahan dari kata Inggris research. Research itu sendiri berasal dari kata re, yang berarti "kembali" dan to search yang berarti mencari. Dengan demikian, arti sebenarnya dari research atau riset adalah "mencari kembali".

Metodologi penelitian adalah cara atau teknis yang dilakukan dalam penelitian. Sebuah penelitian harus berdasarkan pada material data yang akurat, agar hasil dari sebuah penelitian itu dapat dipertanggung jawabkan, baik secara ilmiah maupun pada saat diterapkan, sehingga hasil penelitian itu mempunyai nilai positif.

Selain itu, kegunaan daripada penelitian adalah untuk menyelidiki keadaan dari konsekuensi terhadap suatu keadaan khusus. Secara umum metode penelitian diartikan sebagai cara ilmiah untuk mendapatkan data, dengan tujuan dan kegunaan tertentu

1. Jenis Penelitian

Jenis penelitian yang digunakan oleh penulis pada saat melakukan penelitian adalah jenis penelitian deskriptif kualitatif, adalah data yang diperoleh berupa informasi- informasi sekitar pembahasan, baik secara lisan maupun tulisan.

2. Desain Penelitian

Desain penelitian merupakan keseluruhan dari penelitian mencakup hal-hal yang akan dilakukan peneliti mulai dari membuat hipotesis dan implikasinya secara operasional sampai pada analisis akhir data yang selanjutnya disimpulkan dan diberi saran. 


\section{Variabel Penelitian}

Berdasarkan dengan jenis penelitian maka penulis mengambil variabel penelitian keterlambatan kegiatan Ship To Ship (STS) pada Nipah Transit Anchorage Area (NTAA) yang diageni oleh PT Adhigana Pratama Mulya.

Teknik pengumpulan data dalam penelitian ini adalah dilakukan dengan beberapa cara, berikut uraiannya :

1. Pengamatan (Observası)

Dalam penelitian ini, penulis terjun langsung dalam kegiatan yang dilakukan oleh PT Adhigana Pratama Mulya. Yaitu, dalam menangani kegiatan Ship To Ship (STS). Instrumen yang digunakan dalam teknik ini berupa daftar check list. Check list atau daftar cek adalah pedoman observasi yang berisi tentang daftar semua aspek yang akan diobservasi, observer hanya perlu memberikan tanda ada atau tidak dengan tanda cek $(\sqrt{ })$ tentang aspek observasi.

2. Wawancara (Interview)

Pedoman wawancara ini berisi tentang uraian penelitian yang biasanya dituangkan dalam bentuk daftar pertanyaan agar proses wawancara dapat berjalan dengan baik. Pada teknik ini akan dibuat interview guide or interview schedule (panduan wawancara atau jadwal wawancara) dan menggunakan alat bantu seperti buku catatan, yang berfungsi untuk mencatat semua percakapan dengan sumber data.

3. Penelitian Kepustakaan (Library Research)

Penelitian kepustakaan merupakan teknik pengumpulan data, yaitu dengan cara mempelajari baik itu buku, catatan, arsip maupun dokumen yang berhubungan dengan masalah yang diteliti. Misalnya dengan mencari buku di perpustakaan, tokotoko buku, dan juga melalui internet. 


\section{Teknik Dokumentasi}

Dokumentasi yaitu suatu cara yang digunakan untuk memperoleh atau mengumpulkan data melalui gambar dan dokumen lainnya yang sesuai. Dalam metode ini penulis mengumpulkan data melalui profil PT Adhigana Pratama Mulya.

\section{HASIL DAN PEMBAHASAN}

a. Prosedur Kegiatan Ship To Ship (STS) pada Nipah Transit Anchorage Area (NTAA) yang Diageni oleh PT Adhigana Pratama Mulya

1) Proses Penunjukan Keagenan

Owner/principal mengirim surat penunjukan atau appointment melalui email pada General Agent PT Adhigana Pratama Mulya. Kemudian General Agent memberitahukan kepada sub agent PT Adhigana Pratama Mulya untuk mengageni kapal yang akan melakukan kegiatan Ship To Ship (STS) pada Nipah Transit Anchorage Area (NTAA). Dalam surat penunjukan atau appointment tersebut menjelaskan tentang detail kapal dan jumlah muatan yang akan dibongkar atau dimuat. Setelah mendapatkan surat penunjukan atau appointment dari owner/principal, sub agent memberikan rincian rencana biaya yang akan dikeluarkan pada saat mengageni kapal tersebut yang biasa disebut dengan Estimate Port Disburment Account (EPDA) melalui perantara General Agent. Estimate Port Disburment Account (EPDA) berubah menjadi Final Disburment Account (FDA) jika owner/principal menyetujui rincian biaya yang diberikan.

Setelah owner/principal menyetujui rincian biaya tersebut maka owner/principal berkoordinasi dengan Nahkoda kapal yang akan melakukan kegiatan Ship To Ship (STS) bahwa kapal tersebut diageni oleh PT Adhigana Pratama Mulya. Kemudian sub agent mengirimkan email ke Nahkoda kapal untuk 
menyiapkan formality document sebagai syarat sebelum kapal masuk ke anchorage area.

2) Proses pengurusan dokumen kedatangan kapal

Nahkoda kapal akan mengirimkan sertifikat atau dokumen kapal melalui email kepada agen yang dibutuhkan dalam proses pengurusan dokumen kepada pihak/instansi terkait. Ada pun sertifikat atau dokumen kapal yang dibutuhkan antara lain:

(1) Certificate of Registry

(2) Certificate of Class

(3) International Tonnage Certificate

(4) International Load Line Certificate

(5) Minimum Safe Manning Document

(6) Cargo Ship Safety Construction Certificate

(7) Cargo Ship Safety Equipment Certificate

(8) Cargo Ship Safety Radio Certificate

(9) Safety Management Certificate (SMC)

(10) Document of Compliance (DOC)

(11) International Oil Pollution Prevention Certificate (IOPP)

(12) International Air Pollution Prevention Certificate (IAPP)

(13) International Sewage Pollution Prevention Certificate (ISPP)

(14) International Ship Security Certificate (ISSC)

(15) Port State Control (PSC) 
(16) Ship Sanitation Control Exemption Certificate (SSCEC)

(17) Fire Extinguisher certificate

(18) Inflatable Liferaft Certificate

(19) Anti Fouling Certificate

(20) Ship Particular

(21) CLC Oil Pollution Damage

(22) CLC Bunker Certificate

(23) Wreck Removal Certificate

(24) Ship Security Officer Certificate (SSO) dan Company Security Officer Certificate (CSO)

(25) Update IMO Crew List dalam format excel dan pdf

(26) Last Port Clearance

(27) Maritime Declaration of Health

(28) Vacination List

(29) Stowage Plan

(30) Voyage Memo

(31) Copy BL/Cargo Manifest

Setelah Nahkoda kapal mengirimkan formality document kepada agen maka agen akan membuat beberapa dokumen antara lain:

a) Permohonan Persetujuan Kedatangan Kapal Asing (PKKA) yang ditujukan kepada Direktorat Jenderal Perhubungan Laut. 
b) Setelah Persetujuan Kedatangan Kapal Asing (PKKA) terbit maka sub agent akan membuat dan mengajukan permohonan dan perizinan ke instansi terkait seperti Kantor Kesyahbandaran dan Otoritas Pelabuhan (KSOP), Imigrasi, Bea dan Cukai, Karantina dan Pelindo atau Asinusa Putra Sekawan terkait kedatangan kapal yang akan melakukan kegiatan Ship To Ship (STS).

2) Proses Pengurusan Dokumen Kedatangan Kapal

Nahkoda kapal akan mengirimkan sertifikat atau dokumen kapal melalui email kepada agen yang dibutuhkan dalam proses pengurusan dokumen kepada pihak/instansi terkait seperti Kesyahbandaran dan Otoritas Pelabuhan (KSOP), Karantina, Imigrasi, Bea dan Cukai, serta jasa pandu.

3) Proses Agent on Board

Sebelum agen melakukan on board, agen menunggu informasi dari Nahkoda kapal bahwa kapal yang akan melakukan kegiatan Ship To Ship (STS) akan masuk ke anchorage area. Kemudian Nahkoda memberikan informasi ke station pandu agar kapal dipandu masuk ke anchorage area. Setelah kapal memasuki anchorage area, pihak mooring master naik ke atas kapal untuk mengarahkan Nahkoda agar kapal sejajar saling bersebelahan dengan posisi kiri/portside kapal satu berdekatan dengan sisi kanan/starboard kapal yang satu sebelum melaksanakan kegiatan Ship To Ship (STS). Kemudian agen menginformasikan adanya kegiatan agent on board kepada petugas Kesyahbandaran dan Otoritas Pelabuhan (KSOP), Imigrasi, Bea dan Cukai, Karantina yang akan ikut memeriksa kapal. Petugas dan agen harus dilengkapi dengan alat pelindung diri untuk keselamatan dalam bekerja. 
Perjalanan dimulai dari pelabuhan Sekupang, dari pelabuhan Sekupang menuju Nipah Transit Anchorage Area (NTAA) ditempuh selama satu jam lebih dengan menggunakan speed boat. Setelah tiba di Nipah Transit Anchorage Area (NTAA), agen akan menghubungi pihak kapal dengan menggunakan handly talky (HT) agar mengibarkan bendera kuning sebagai tanda bahwa kapal siap untuk diperiksa oleh petugas Karantina. Petugas Karantina naik ke atas kapal untuk memastikan bahwa kapal bebas dari hama dan ABK bebas dari penyakit. Setelah pemeriksaan selesai, maka petugas Karantina menerbitkan Free Pratique atau Certificate of Pratique (COP) dan mengintruksikan Nahkoda untuk menurunkan bendera kuning yang menandakan bahwa kapal telah diperiksa oleh petugas Karantina.

Kemudian pemeriksaan dilanjut oleh petugas Kesyahbandaran dan Otoritas Pelabuhan (KSOP), Imigrasi, Bea Cukai dan agen. Petugas imigrasi melakukan stemp in pada paspor kru kapal dan menahan untuk sementara paspor kru kapal sampai kegiatan Ship To Ship (STS) selesai.

Petugas Bea dan Cukai melakukan pemeriksaan pada gudang atau tempat penyimpanan barang, muatan serta barang apa saja yang ada di atas kapal. Setelah melakukan pemeriksaan maka petugas Bea dan Cukai akan menerbitkan Surat Pernyataan Pemeriksaan atau Declaration of Inspection.

Petugas Kesyahbandaran dan Otoritas Pelabuhan (KSOP) akan memeriksa kelengkapan sertifikat kapal serta masa berlaku dari sertifikat tersebut. Setelah pengecekan, petugas Kesyahbandaran dan Otoritas Pelabuhan (KSOP) akan menerbitkan Izin Labuh, Olah Gerak, dan Izin Ship to Ship (STS) dan diserahkan kepada Nahkoda sebagai tanda bahwa kapal 
telah mendapatkan izin melakukan kegiatan bongkar atau muat dari Kesyahbandaran dan Otoritas Pelabuhan (KSOP). Pemeriksaan dilakukan dari kapal satu ke kapal yang berikutnya.

4) Proses Pengurusan Dokumen Keberangkatan Kapal

Kurang lebih dari 24 jam sebelum selesai melakukan bongkar muat Nahkoda memberikan informasi kepada agen melalui email tentang rencana komplit pemuatan atau pembongkaran serta memberitahu tujuan kapal ke pelabuhan selanjutnya. Kemudian agen memberikan informasi kepada pihak/instansi dan menyiapkan dokumen-dokumen terkait tentang rencana keberangkatan kapal.

Setelah dokumen selesai agen akan melakukan kembali kegiatan on board. Sebelum agent on board, agen terlebih dahulu memberikan informasi ke pandu terkait keberangkatan kapal. Kemudian agen mengajukan permohonan keberangkatan kapal dan dokumen pendukung lainnya ke Kesyahbandaran dan Otoritas Pelabuhan (KSOP) untuk penerbitan Surat Persetujuan Berlayar (SPB). Sebelum Surat Persetujuan Berlayar (SPB) diterbitkan, petugas Kesyahbandaran dan Otoritas Pelabuhan (KSOP) akan memeriksa dokumen pendukung sebagai persyaratan untuk diterbitkannya Surat Persetujuan Berlayar (SPB). Apabila telah dinyatakan lengkap dan memenuhi persyaratan maka Surat Persetujuan Berlayar (SPB) akan diterbitkan. Setelah kapal mendapatkan Surat Persetujuan Berlayar (SPB) maka kapal dinyatakan sudah bisa meninggalkan anchorage area. Lalu agen dan petugas imigrasi turun dari kapal dan kapal akan di pandu untuk meninggalkan anchorage area.

b. Hambatan yang mengakibatkan keterlambatan dalam kegiatan ship to ship (STS) pada kapal MT VL Nichioh dan MT Lipari di Nipah Transit Anchorage Area (NTAA) yang diageni oleh PT Adhigana Pratama Mulya 
1) Untuk penerbitan dokumen izin kegiatan bongkar muat yang dilakukan oleh petugas Kesyahbandaran dan Otoritas Pelabuhan (KSOP) terkadang ada beberapa sertifikat kapal yang masa berlakunya telah habis dan harus diperbaharui. Salah satu sertifikat dari kapal MT Lipari masa berlakunya telah habis yaitu Ship Sanitation Control Exemption Certificate (SSCEC). Maka sertifikat tersebut harus diperbaharui dan memakan waktu yang cukup lama. Selain itu, dalam proses pengurusan dokumen kapal terkendala akibat jarak antara instansi satu ke instansi lainnya berjauhan sehingga membutuhkan waktu yang cukup lama dalam pengurusan dokumen kapal.

2) Perawatan yang tidak dilakukan secara rutin pada alat bongkar muat kapal MT Lipari sangat berpengaruh dalam keterlambatan proses Ship To Ship (STS). Apabila alat bongkar muat kapal tanker minyak kurang terawat maka akan menimbulkan masalah. masalah seperti:

1) Cairan muatan tidak mengalir yang disebabkan oleh pompa yang belum dicerat, pompa yang tidak terisi penuh cairan muatan, udara bocor ke pipa isap, tinggi pipa isap terlalu tinggi, saringan isap buntu, RPM terlalu rendah.

2) Cairan yang mengalir tidak banyak yang disebabkan pompa tidak terisi penuh dengan cairan muatan, bell mouth isap tidak terendam cairan muatan, saringan isap sebagian buntu, RPM rendah, terdapat udara atau gas didalam saluran isap, dan viscositas cairan muatan encer.

3) Pompa makan banyak tenaga yang disebabkan oleh RPM terlalu tinggi, viscositas muatan lebih tinggi, muatan lebih berat, impeller menggesek mouth ring, dan rate pompa terlalu tinggi.

4) Bell Ring Overhead yang disebabkan oleh pompa tidak lurus, minyak pelumas kurang, minyak pelumas terlalu penuh, as bengkok, kelainan di thrust bearing, ada kotoran di bearing dan 
kelainan di oil ring.

5) Mechanical Seal bocor yang disebabkan oleh kerusakan/aus pada mechanical seal. kerusakan pada "O" ring, coalar tidak duduk, ada kotoran pada permukaan seal, baut/mur pengikat gland longgar, dan pipa untuk flushing mechanical seal buntu.

3) Cuaca buruk mempengaruhi pada saat proses sandarnya kapal untuk melakukan kegiatan Ship To Ship (STS). Seperti angin kencang yang mengakibatkan tingginya ombak sehingga proses penyandaran kapal MT VL Nichioh dan MT Lipari mengalami sedikit keterlambatan dari waktu yang ditentukan sebelumnya. Selain itu, perjalanan yang ditempuh oleh agen dan petugas ketika hendak ke kapal dari pelabuhan Sekupang ke Nipah Transit Anchorage Area (NTAA) menjadi lebih lama dari biasanya yang berdampak pada kegiatan bongkar muat. Karena kegiatan bongkar muat tidak bisa dilakukan sebelum dokumen-dokumen perizinan bongkar muat diserahkan kepada Nahkoda kapal MT VL Nichioh dan MT Lipari.

c. Upaya yang dilakukan untuk mencegah keterlambatan dalam kegiatan ship to ship (STS) pada kapal MT VL Nichioh dan MT Lipari di Nipah Transit Anchorage Area (NTAA) yang diageni oleh PT Adhigana Pratama Mulya

1) Sebelum dokumen kapal MT Lipari diperiksa oleh petugas Kesyahbandaran dan Otoritas Pelabuhan (KSOP), agen akan menginformasikan kepada Nahkoda kapal MT Lipari mengenai Ship Sanitation Control Exemption Certificate (SSCEC) yang masa berlakunya telah habis agar segera diperbaharui. Agen berkoordinasi dengan general agent mengenai biaya pengurusan pembaharuan sertifikat tersebut. Kemudian general agent akan menginformasikan kepada owner/principal kapal MT Lipari, jika owner/principal menyetujui biaya tersebut maka agen akan mengurus sertifikatnya. Setelah menunggu setifikat 
diperbaharui maka agen akan membuat dokumen dan mengajukan untuk penerbitan izin kegiatan bongkar muat kapal MT VL Nichioh dan MT Lipari.

2) Memberikan saran kepada pihak kapal MT Lipari untuk melakukan pemeliharaan pompa dengan cara minyak pelumas bearing diganti setiap 600 jam kerja, cooler L.O. digosok tiap 300 jam kerja, dan saringan isap dibersihkan setiap bulan.

3) Tetap mengupayakan agar dokumen secepat mungkin tiba di atas kapal dan tetap mengutamakan keselamatan pada saat proses pengantaran dokumen ke atas kapal agar proses kegiatan Ship To Ship (STS) dapat dilaksanakan sesuai dengan jadwal yang ditentukan.

\section{KESIMPULAN}

a) Beberapa sertifikat kapal yang masa berlakunya telah habis dan harus diperbaharui. Untuk itu agen harus memeriksa kembali sertifikat-serfikat sebelum kapal tiba agar penerbitan izin kegiatan bongkar muat berjalan lancar.

b) Kurangnya perawatan alat bongkar muat yang dilakukan oleh kru kapal sehingga mengakibatkan beberapa masalah yang terjadi saat proses Ship To Ship (STS) berlangsung.

c) Adanya cuaca buruk seperti angin kencang yang mengakibatkan ombak besar sehingga kapal terhambat untuk sandar ke kapal lain untuk melakukan Ship To Ship (STS). Selain itu, perjalanan yang ditempuh oleh agen dan petugas ketika hendak ke kapal dari pelabuhan Sekupang ke Nipah Transit Anchorage Area (NTAA) menjadi lebih lama dari biasanya yang berdampak pada kegiatan bongkar muat. Karena kegiatan bongkar muat tidak bisa dilakukan sebelum dokumen-dokumen perizinan bongkar muat diserahkan kepada Nahkoda kapal. 


\section{DAFTAR PUSTAKA}

[1]. Departemen Pendidikan Indonesia. (2008). Kamus Besar Bahasa Indonesia. Jakarta: Balai Pustaka.

[2]. Departemen Kelautan Book. (2005). Prosedur Clearence in/out. Special Edition.

[3]. Capt. Sutiyar, dkk. (1994). Kamus Istilah Pelayaran dan Perkapalan. Jakarta: Pustaka Beta. Kokasih, E. dan Soewedo, H. (2014). Manajemen Perusahaan Pelayaran. Semarang: Yrama Widya.

[4]. Sujatmiko, C.D. (1994). Prosedur Dokumen Kapal.

[5]. M. Kusumaatmadja, Pembinaan Pelayaran Nasional dalam Rangka Penegakan Wawasan Nusantara, yang dikutip dari Graciella Eunika Sumenda, Keberadaan Asas Cabotage Terhadap Perusahaan Angkutan Laut Dalam Undang - Undang Nomor 17 Tahun 2008 Tentang Pelayaran, Lex et Societatis, Vol. V, No. 7, September 2017.

[6]. Peraturan Menteri Perhubungan Republik Indonesia Nomor PM 74. (2016). Penyelenggaraan dan Pengusahaan Angkutan Laut.

[7]. Peraturan Menteri Perhubungan Republik Indonesia Nomor PM 82. (2014). Tata Cara Penerbitan Surat Persetujuan Berlayar.

[8]. Peraturan Menteri Perhubungan Republik Indonesia Nomor PM 11. (2016). Penyelenggaraan dan Pengusahaan Keagenan Kapal.

[9]. SOP. (2013). Prosedur Kegiatan Ship To Ship. Batam: PT Adhigana Pratama Mulya. Undang-Undang Republik Indonesia Nomor 17 Tahun 2006. Tentang Kepabeanan. Undang-Undang Republik Indonesia Nomor 17 Tahun 2008. Tentang Pelayaran.

[10]. Info Maritim, 2016, Organisasi Keagenan Kapal, (https://banggaplex.blogspot.com/2016/01/ilmu-keagenankapal.html, diakses tanggal 6 Januari 2016) 